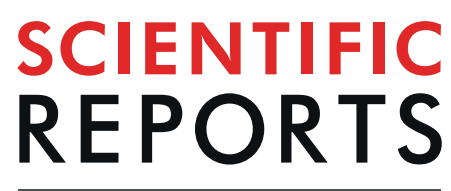

natureresearch

\title{
Effect of anti-inflammatory treatment on systemic inflammation, immune function, and endometrial health in postpartum dairy cows
}

\author{
O. Bogado Pascottini ${ }^{1 *}$, S. J.Van Schyndel ${ }^{1}$, J. F. W. Spricigo ${ }^{2}$, M. R. Carvalho ${ }^{2}$, B. Mion ${ }^{2}$, \\ E. S. Ribeiro ${ }^{2} \&$ S. J. LeBlanc ${ }^{1}$
}

Systemic inflammation (SI) is increasingly studied in several species because it may be central in many metabolic disturbances and be a risk factor for clinical disease. This proof-of-concept study evaluated the effects of the anti-inflammatory drug meloxicam on markers of SI and energy metabolism, polymorphonuclear neutrophil (PMN) function, and endometritis in clinically healthy postpartum dairy cows. Cows received meloxicam $(0.5 \mathrm{mg} / \mathrm{kg}$ of body weight; $\mathrm{n}=20)$ once daily for 4 days $(10-13$ days postpartum) or were untreated $(n=22)$. Blood samples were collected $-7,1,3,5,7,10,11,12$, $13,14,18,21,28$, and 35 days relative to calving to measure serum concentrations of metabolic and inflammatory markers. Function of peripheral blood PMN were evaluated at 5, 10, 14, and 21, and proportion of PMN in endometrial cytology were performed at 5, 10, 14, 21, 28 and 35 days postpartum. Meloxicam decreased serum haptoglobin from the second until the last day of treatment, and improved indicators of energy metabolism (lesser $\beta$-hydroxybutyrate and greater insulin-like growth factor- 1 during treatment, and greater glucose at the end of treatment than control cows). This improved PMN function at 14 days postpartum, but the endometrial inflammatory status was not affected.

The metabolic profile in obese humans and humans with metabolic syndrome is commonly characterized by upregulated lipolysis, insulin resistance, and systemic inflammation (SI) ${ }^{1}$. The latter are risk factors for type 2 diabetes and cardiovascular disease and are associated with reproductive tract dysfunction ${ }^{2}$. Similarly, the early postpartum period for a lactating dairy cow is a challenging time with increased risk of metabolic and infectious diseases including metritis and endometritis ${ }^{3}$. Around parturition, cows concurrently have a decrease in feed dry matter intake (DMI) and an increase in SI, although it is unclear if one is causative for the other ${ }^{4}$. Postpartum SI is caused by altered metabolism, with several probable contributing causes, including excessive fat mobilization which leads to the production of pro-inflammatory cytokines, tumor necrosis factor alpha (TNF)- $\alpha$, and interleukin (IL)-6 $6^{5,6}$. While peripheral insulin insensitivity is an adaptative change to support lactation, these cytokines inhibit intracellular signaling of insulin, heightening insulin insensitivity and exacerbating the release of non-esterified fatty acids (NEFA) from adipose tissue ${ }^{7}$. Proinflammatory cytokines also stimulate the production of acute phase proteins such as haptoglobin, which is commonly used as a biomarker of inflammation ${ }^{8-10}$. Elevated concentrations of circulating NEFA, TNF- $\alpha$, IL- 6 accompanied by insulin resistance resemble sterile inflammation and metabolic syndrome in obese humans and humans with non-alcoholic fatty liver disease ${ }^{11,12}$. In dairy cattle, this metabolic change is mainly due to the homeorhetic shift to support milk production, when nutrient demand exceeds dietary intake, resulting in a state of negative energy balance (NEB) ${ }^{13}$. Several studies have highlighted associations between biomarkers of metabolic stress and inflammation, and reproductive tract disease in dairy cows ${ }^{14-16}$.

In dairy cows, a robust but well-regulated postpartum uterine inflammatory response is necessary for the elimination of pathogens, resumption of ovarian function, and avoidance of reproductive disease ${ }^{17,18}$. Rapid 
postpartum recruitment of a high number of polymorphonuclear leukocytes (PMN; neutrophils) to the uterine lumen is associated with better uterine health and reproductive performance ${ }^{19,20}$. However, metabolic disorders and elevated circulating concentrations of pro-inflammatory cytokines can lead to compromised immune cell function and dysregulation of inflammation in the uterus ${ }^{21}$. Endometritis (> $5 \% \mathrm{PMN}$ in endometrial cytology diagnosed around the fifth week postpartum) affects 15 to $35 \%$ of dairy cows and substantially impairs their fertility ${ }^{22,23}$. Endometritis is chronic, localized, often without concurrent bacterial infection, and so is currently understood as a manifestation of dysregulated inflammation, the specific causes of which are not well characterized $^{18,24}$. Elevated levels of NEFA compromise PMN proliferation and function ${ }^{25-27}$. Cows that subsequently developed endometritis had elevated levels of NEFA and $\beta$-hydroxybutyrate (BHB) in the first three weeks postpartum $^{16}$. Compared with healthy cows, those diagnosed with metritis or endometritis were found to have higher serum concentrations of haptoglobin ${ }^{8}$, TNF- $\alpha$, IL-1- $\beta$, and IL- 6 and lower concentrations of insulin and IGF-1, preceding the diagnosis of disease ${ }^{15}$.

The use of non-steroidal anti-inflammatory drugs (NSAID) in humans reduced SI associated with insulin resistance and the risk of colon and rectal cancer by inhibiting the cyclooxygenase-2 (COX-2) pathway, tumor formation, and tumor growth ${ }^{11}$. Studies have also shown a reduction in fasting plasma glucose, total cholesterol, triglycerides, and insulin clearance in humans with type 2 diabetes administered high-dose NSAID treatments ${ }^{28}$. In grazing dairy cows, Priest et al. ${ }^{29}$ investigated the effects of postpartum NSAID treatment ( 3 injections at intervals of 3 days) between 21 and 31 days postpartum on endometritis ( $\geq 14 \% \mathrm{PMN}$ in endometrial cytology, diagnosed at 14 days postpartum). They found no effect of treatment on uterine PMN percentage, postpartum anovulatory interval, or milk production, but documented increased pregnancy rate in high-PMN cows that were treated with carprofen. In a study comparing administration of oral sodium salicylate, meloxicam, or placebo, whole-lactation milk and protein yields were greater in cows treated with NSAID ${ }^{30}$. Similarly, cows treated with oral meloxicam produced more milk in early lactation, had reduced odds of subclinical mastitis, and reduced odds of early lactation culling ${ }^{31}$. In a recent study, Montgomery et al. ${ }^{32}$ explored the mechanistic role of inflammatory signaling in glucose and energy metabolism of dairy cows treated with sodium salicylate in drinking water in the first week postpartum. Although treated mature transition cows tended to suppress whole-body glucose turnover, no major differences were found in markers of SI and energy metabolism. Meloxicam, a NSAID approved for use in dairy cattle in Canada, selectively inhibits COX-2. However, there is limited research exploring the use of meloxicam to mitigate postpartum SI and treat reproductive tract inflammatory dysregulation in dairy cattle.

The objective of this proof-of-concept experiment was to assess the effects of NSAID treatment on the dynamics of SI, energy metabolism, innate immune response, and uterine health. The hypothesis was that meloxicam would decrease SI, thus improving PMN function and decreasing reproductive tract inflammation assessed by endometrial cytology.

\section{Materials and Methods}

Study design. This non-randomized controlled trial was conducted from April to August 2018 at the University of Guelph Livestock Research and Innovation Centre, Dairy Facility (Elora, ON, Canada). Animal procedures were approved by the University of Guelph Animal Care Committee, and cows were managed according to the guidelines set by the Dairy Farmers of Canada and the National Farm Animal Care Council. The sample size calculation was based on the effect of anti-inflammatory treatment using $80 \%$ power and a $95 \%$ confidence level. The sample size of 20 cows per group was based on detection of differences of $0.5 \pm 0.5 \mathrm{~g} / \mathrm{L}$ (mean $\pm \mathrm{SD}$ ) in serum haptoglobin or $10 \pm 10 \%$ points of PMN in endometrial cytology samples. Only cows considered clinically healthy from calving to 35 days postpartum were included (having unassisted calving, and no retained placenta, metritis or other clinical disease before or during the study period). Initially, 59 non-lactating pregnant Holstein cows ( 24 nulliparous and 35 parous) were enrolled 14 days before the expected calving date (266 days after the last insemination). Seventeen cows were excluded from the experiment due to injury in the prepartum period $(n=1)$, dystocia $(n=7)$, retained placenta $(n=3)$, or clinical disease $(n=6$; metritis, displaced abomasum, or ketosis). The final sample consisted of 42 healthy Holstein cows ( 17 nulliparous and 25 parous; parity $1.3 \pm 1.3$ ), with an average body condition score (BCS) at inclusion of $3.8 \pm 0.2$ out of 5 . Dry cows were housed in free-stall pens and moved to individual calving pens 48 hours before expected calving, or if presenting external signs of preparation for calving (e.g., swelling of the vulva and relaxation of the pelvic ligaments). Five days after calving, healthy cows were relocated to a free-stall lactating pen, where they remained until the end of the experiment (35 days postpartum). In the free-stall pens, daily feed DMI was measured by individual automated feed bins (Insentec B.V., Marknesse, Netherlands). In the individual maternity pen, the amount of offered and refused feed was weighed daily by trained farm personnel. The diets and chemical composition of the lactating cow total mixed ration are described in Supplementary Table A. Cows were fed once daily $(1300 \mathrm{~h})$ for ad libitum intake after cleaning out of each feed bin. Milking was carried out twice daily $(0500$ and $1700 \mathrm{~h})$ in a rotary parlour. At inclusion, cows were assigned to one of two experimental treatment groups to deliberately balance for parity and BCS. Experimental groups consisted of control $(\mathrm{CON}, \mathrm{n}=22$; parity $1.3 \pm 1.7$ and BCS $3.8 \pm 0.2)$ and meloxicam (MEL, $\mathrm{n}=20$; parity $1.2 \pm 1.3$ and BCS $3.9 \pm 0.2)$ treatments. MEL received subcutaneous injections of meloxicam $(0.5 \mathrm{mg} / \mathrm{kg}$ of body weight; Metacam, Boehringer Ingelheim Canada Ltd., Burlington, ON, Canada) once daily on 10, 11, 12 and 13 days postpartum (between 1000 and 1100).

Blood samples. Blood samples were collected by coccygeal venipuncture into vacuum serum tubes free of anticoagulant (BD Vacutainer Precision Glide, Becton Dickinson, Franklin Lakes, NJ) on -7, 1, 3, 5, 7, 10, 11, 12, $13,14,18,21,28$ and 35 days relative to calving (between 0800 and $0900 \mathrm{~h}$ ). Within 2 hours of collection, samples were centrifuged at $1,500 \times g$ for $15 \mathrm{~min}$ and serum was stored in aliquots at $-20^{\circ} \mathrm{C}$ until analysis. 
Glucose tolerance test. A simplified glucose tolerance test (GTT) ${ }^{33,34}$ was performed at 5, 10, and 14 days postpartum (between 0900 and $1000 \mathrm{~h}$ with feed withheld $3 \mathrm{~h}$ before and during the GTT). Briefly, cows were restrained to allow jugular intravenous infusion of $0.25 \mathrm{mg}$ of dextrose $/ \mathrm{kg}$ of body weight (dextrose $50 \%$, Vétoquinol Canada Inc., Lavaltrie, QC, Canada) over $2 \mathrm{~min}$. Blood samples were collected immediately before $(0 \mathrm{~min})$, and 10, 60 and $80 \mathrm{~min}$ after the dextrose infusion. Within 2 hours, GTT blood samples were centrifuged at $1,500 \times g$ for $15 \mathrm{~min}$ and serum stored at $-20^{\circ} \mathrm{C}$ until analysis.

Blood metabolites. Serum samples were analyzed by the University of Guelph Animal Health Laboratory (Guelph, ON, Canada). Albumin, globulin, total protein, urea, gamma-glutamyl transferase (GGT), aspartate aminotransferase (AST), glutamate dehydrogenase (GLDH), total calcium, and glucose serum concentrations were measured using an autochemistry analyzer (Cobas 6000 c 501, Roche Diagnostics, Indianapolis, IN). NEFA and BHB serum concentrations were measured using Randox NEFA and BHB kits (Randox Laboratories, Canada Ltd., Mississauga, ON, Canada). Haptoglobin concentration was measured by the hemoglobin binding capacity method $^{35,36}$. IGF-I serum concentration was measured using a human immunoassay (Quantikine ELISA, R\&D Systems, Minneapolis, MN). Serum insulin concentration was determined using a bovine-specific insulin ELISA (Mercodia AB, Uppsala, Sweden). A summary of the assay names, analytical sensitivities, and intra-assay coefficients of variation for each of the serologic variables are presented in Supplementary Table B.

Neutrophil function. Circulating PMN function assays were performed at 5, 10, 14, and 21 days postpartum. Blood samples were collected (between 0800 and $0900 \mathrm{~h}$ ) by coccygeal venipuncture into tubes containing acid citrate dextrose (Vacutainer, Becton Dickinson, Franklin Lakes, NJ) and processed within 3 hours of collection. The PMN isolation protocol was performed as described by Pascottini et al. ${ }^{37}$. In the final isolation step (sample free of visible hemoglobin) the cell pellet was resuspended in $500 \mu \mathrm{L}$ of $1 \times \mathrm{PBS}$. A hemocytometer chamber and trypan blue exclusion were used to assess cell concentration and viability, with only samples with $>90 \%$ PMN viability being accepted. Cytospin slides were prepared and stained (Wright's), and cells were tested for purity, with only samples containing $>80 \%$ PMN being accepted. Samples were centrifuged and the pelleted PMN were diluted to a concentration of $1 \times 10^{6} / \mathrm{mL}$ using $1 \times$ concentrated PBS with $10 \%$ filtered fetal bovine serum (FBS, Invitrogen, Burlington, ON, Canada).

For the oxidative burst assay ${ }^{37}, 200 \mu \mathrm{L}$ of the PMN suspension and $2 \mu \mathrm{L}$ of $1 \mathrm{mM} 2^{\prime}, 7^{\prime}$-dih ydro-dichlorofluorescein-diacetate (Molecular Probes, Eugene, OR) were incubated in two flow cytometry tubes for $15 \mathrm{~min}$ in the dark at $37^{\circ} \mathrm{C}$ under gentle agitation. Then, $200 \mu \mathrm{L}$ of phorbol myristate acetate (Sigma-Aldrich, St. Louis, MO; $25 \mathrm{ng} / \mathrm{mL}$ in PBS/FBS) was added to the treatment tube and $200 \mu \mathrm{L}$ of PBS $(1 \times)$ containing $10 \%$ FBS was added to the control tube. Tubes were incubated for $15 \mathrm{~min}$ at $37^{\circ} \mathrm{C}$ under gentle agitation and then placed on ice in darkness until flow cytometry analysis.

For the phagocytosis assay ${ }^{37}$, activated normal cow serum was produced for the whole experiment using serum from 20 healthy lactating Holstein cows. Next, $100 \mathrm{mg}$ of Zymosan A from Saccharomyces cerevisiae (Sigma-Aldrich) was added per $10 \mathrm{~mL}$ of pooled serum, incubated at $37^{\circ} \mathrm{C}$ for $60 \mathrm{~min}$ under gentle rotation, centrifuged at $2,500 \times g$ for $15 \mathrm{~min}$, filtered, and stored at $-80^{\circ} \mathrm{C}$. In a flow cytometry tube, $200 \mu \mathrm{L}$ of the PMN suspension and $50 \mu \mathrm{L}$ of thawed bovine serum with Zymosan A were incubated with fluorescently labeled 1- $\mu \mathrm{m}$ beads (TransFluo-Spheres Fluorescent Microspheres, Molecular Probes) in the darkness for $30 \mathrm{~min}$ at $37^{\circ} \mathrm{C}$. A negative control consisted of PMN incubated without fluorescent beads. After incubation, $200 \mu \mathrm{L}$ of flow buffer was added to each tube and placed on ice in darkness until flow cytometry analysis.

For the DQ-ovalbumin assay, to measure proteolytic degradation following endocytosis ${ }^{37}$, two tubes containing $1 \times 10^{6} \mathrm{PMN}$ in $120 \mu \mathrm{L}$ of Dulbecco's modified Eagle's medium (Gibco/Thermo Fisher Scientific, Waltham, MA) supplemented with $10 \% \mathrm{FBS}$ were incubated at $37^{\circ} \mathrm{C}$ under gentle agitation for $45 \mathrm{~min}$ in the dark. One of the tubes served as control and the other was supplemented with $10 \mu \mathrm{L}$ of DQ-ovalbumin $(10 \mu \mathrm{g} / \mathrm{mL}$; Thermo Fisher Scientific, Eugene, OR). After incubation, cells were washed with PBS, diluted in $200 \mu \mathrm{L}$ of flow buffer, allocated to flow cytometry tubes on ice, and protected from light until analysis.

PMN samples were analyzed via flow cytometry (FACSCanto, BD Biosciences). The events threshold was set at 10,000 around the area of interest (PMN population) on cytograms of forward versus side scatter. The fluorescence exhibited in the oxidative burst and DQ-ovalbumin assay were measured at $530 \mathrm{~nm}$ on a log scale. Phagocyted fluorescent beads were measured at $780 \mathrm{~nm}$ on a log scale. Data were analyzed using FlowJo software (Tree Star, Ashland, OR). A gate was labeled around the PMN population and the cytograms were transformed to histograms. Control and treatment PMN histograms were visualized to corroborate the functionality of the assays. For all the PMN function assays, the difference in the median fluorescence intensity (MFI) was calculated relative to the MFI of the respective negative control. For oxidative burst, the shift in the percentage of stimulated PMN relative to the negative control, and for phagocytosis, the percentage of PMN that engulfed cells, were also evaluated.

Endometrial cytology. Cytobrush samples were collected at 5, 10, 14, 21 days postpartum, as described by Van Schyndel et al. ${ }^{38}$. Briefly, after cleansing the perineal area of the cow, the cytobrush rod (covered with a plastic sanitary sheath) was introduced into the vagina and guided through the cervix via rectal palpation. Once the tip of the rod reached the uterine body, the sanitary sheath was pulled back, the cytobrush was exposed from the rod and rotated against the dorsal wall of the endometrium ${ }^{39}$. The cytobrush was retracted into the rod and removed from the vagina, then rolled onto a microscope slide, air-dried, and stained using May-Grunwald-Giemsa stain. Three hundred cells were counted per slide in multiple fields and the PMN to epithelial cells ratio was averaged between the outcomes of two observers (Lin's concordance correlation coefficient $\rho c=0.77(0.71-0.82)$ ). 


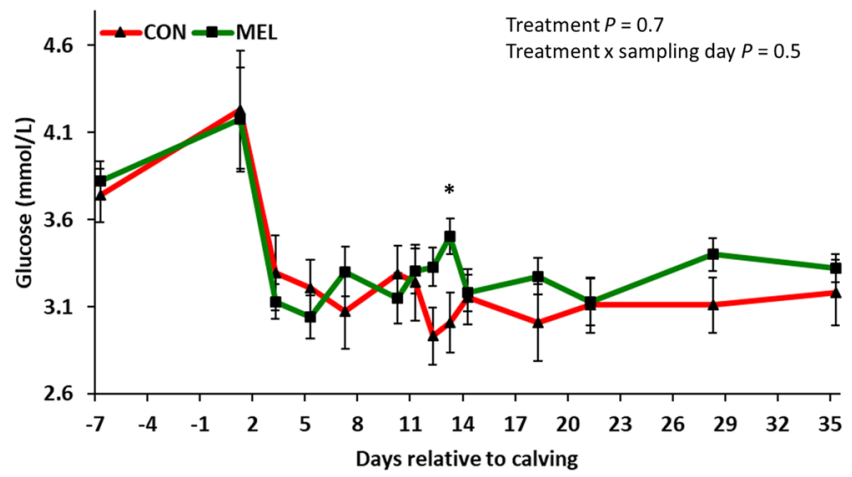

Figure 1. LSM (accounting for parity and body condition score) \pm SE of serum glucose concentrations in 42 Holstein cows. Experimental groups consisted of control $(\mathrm{CON} ; \mathrm{n}=22)$ and meloxicam treated cows $(\mathrm{MEL}$, $\mathrm{n}=20$ ). MEL received meloxicam $(0.5 \mathrm{mg} / \mathrm{kg}$ of body weight) once daily for 4 days (10 to 13 days postpartum). MEL had higher serum glucose concentrations when compared to CON at 13 days postpartum $(P=0.04)$.

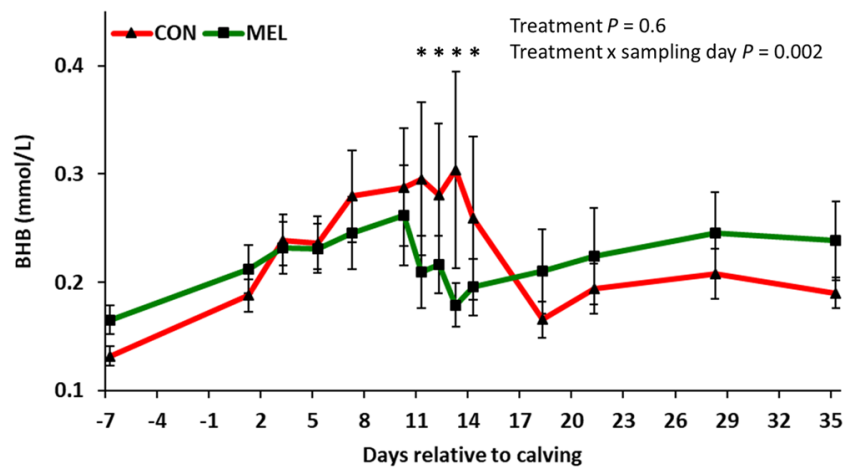

Figure 2. $\log _{10}$-scale LSM (accounting for parity and body condition score) \pm SE of serum $\beta$-hydroxybutyrate (BHB) concentrations in 42 Holstein cows. Experimental groups consisted of control (CON; $n=22)$ and meloxicam treated cows (MEL, $\mathrm{n}=20)$. MEL received meloxicam $(0.5 \mathrm{mg} / \mathrm{kg}$ of body weight) once daily for 4 days (10 to 13 days postpartum). MEL had lower serum BHB concentrations when compared to CON at 11,12 , 13 , and 14 days postpartum $(P=0.01,0.04,0.001$, and 0.05 , respectively).

Statistical analyses. The statistical analyses were performed using R-core (version 3.6.1; R Core Team, Vienna, Austria). Results are expressed as least squares means and standard errors. Variables were analyzed by Shapiro-Wilk's test and when not normally distributed $(P<0.05)$, were $\log _{10}$ transformed. The effect of explanatory variables on dependent variables were fitted in mixed linear regression models. Treatment (CON and MEL), sampling day, and their interaction were forced into each model. Parity (nulliparous and parous) and BCS at enrollment $(\leq 3.5$ and $\geq 3.75)$ were offered as covariates for all models. Sampling day was included as a repeated observation within the random cow factor. For results from the simplified GTT, the area between insulin and glucose curves was calculated using the trapezoid method ${ }^{33}$ and fitted in mixed linear regression models including parity and BCS as covariates. First-order interactions of treatment with each covariate were tested and excluded when $P>0.05$. The overall effects of predictor variables (treatment, sampling day, and treatment $\times$ sampling day interaction) were assessed with a type III analysis of variance and differences between levels of predictor variables were assessed using Tukey's post hoc test.

\section{Results}

DMI and milk production. The daily DMI for CON and MEL groups are presented in Supplemental Fig. 1. No differences in DMI were found between experimental groups at any timepoint $(P=0.3)$. Mean milk production to 35 day postpartum was not different between experimental groups $(P=0.8 ; 33.2 \pm 10.6 \mathrm{~kg}$ for CON and $33.5 \pm 10.7 \mathrm{~kg}$ for MEL; Supplemental Fig. 2).

Blood metabolites. All serum metabolites changed $(P<0.05)$ over time in both experimental groups. MEL had higher serum glucose concentrations than CON at the last day of meloxicam treatment (13 days postpartum; $P=0.04$; Fig. 1). Although serum NEFA concentrations were similar between experimental groups $(P=0.9$; Supplemental Fig. 3), serum BHB concentrations were lower in MEL than CON during meloxicam treatment (11, 12,13 , and 14 days postpartum; $P=0.01,0.04,0.001$, and 0.05 , respectively; Fig. 2). Similarly, serum haptoglobin concentrations were lower in MEL on 11,12 , and 13 days postpartum $(P=0.05,0.02$, and 0.05 , respectively; Fig. 3). Serum IGF-1 concentrations were stable in MEL from the first until the last day of treatment but decreased 


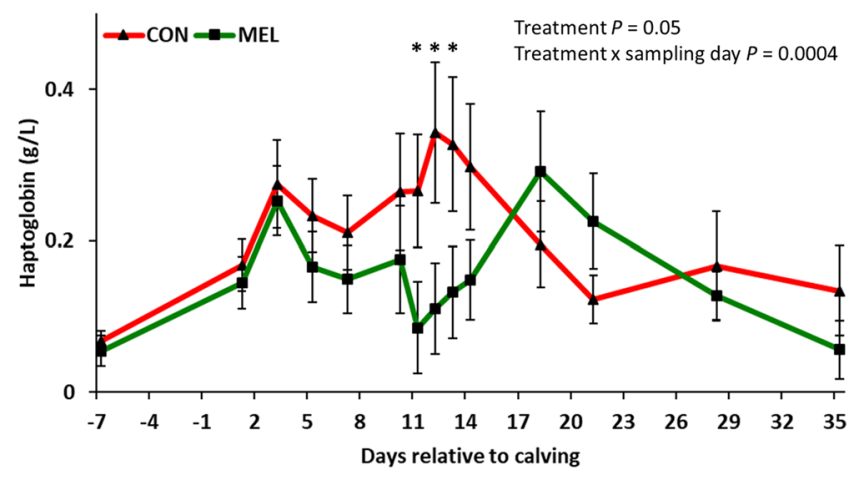

Figure 3. $\log _{10}$-scale LSM (accounting for parity and body condition score) \pm SE serum haptoglobin concentrations in 42 Holstein cows. Experimental groups consisted of control $(\mathrm{CON} ; \mathrm{n}=22)$ and meloxicam treated cows (MEL, $\mathrm{n}=20)$. MEL received meloxicam $(0.5 \mathrm{mg} / \mathrm{kg}$ of body weight) once daily for 4 days (10 to 13 days postpartum). MEL had lower serum haptoglobin concentrations when compared to CON at 11, 12, and 13 days postpartum $(P=0.05,0.02$, and 0.05 , respectively).

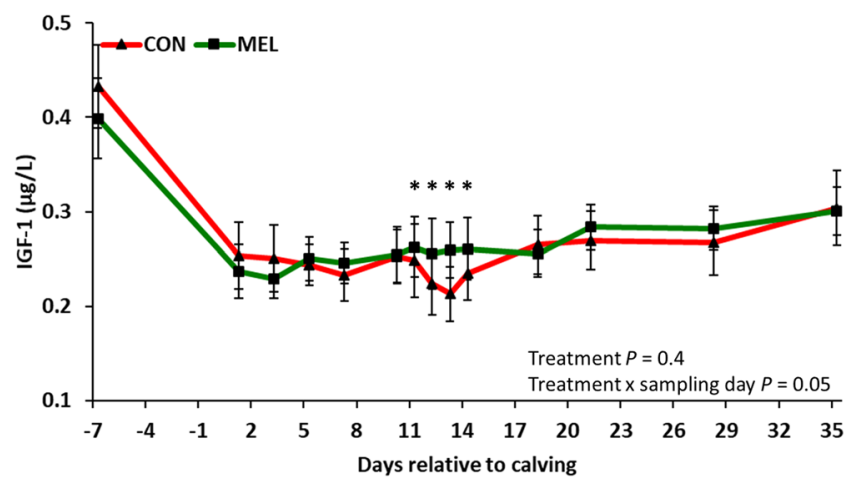

Figure 4. $\log _{10}$-scale LSM (accounting for parity and body condition score) \pm SE of serum insulin-like growth factor-1 (IGF-1) concentrations in 42 Holstein cows. Experimental groups consisted of control $(\mathrm{CON} ; \mathrm{n}=22)$ and meloxicam treated cows (MEL, $\mathrm{n}=20)$. MEL received meloxicam $(0.5 \mathrm{mg} / \mathrm{kg}$ of body weight $)$ once daily for 4 days (10 to 13 days postpartum). MEL had higher serum IGF-1 concentrations when compared to CON at 11 , 12,13 , and 14 days postpartum $(P=0.04,0.002,0.0003$, and 0.007 , respectively).

in CON, such that IGF-1 concentrations were greater in the treated cows $(11,12,13$, and 14 days postpartum; $P=0.04,0.002,0.0003$, and 0.007, respectively; Fig. 4). Total calcium, total protein, albumin, globulin, cholesterol, and urea were not different between CON and MEL groups at any time point $(P>0.2$; Supplemental Figs. 4-9). None of the serologic concentrations of liver enzymes (GGT, AST, and GLDH) were different between experimental groups at any timepoint $(P>0.7$; Supplemental Figs. 10-12).

Glucose tolerance test. The response of serum glucose and insulin to dextrose infusion at each time point of the GTT $(0,10,60$, and $80 \mathrm{~min})$ is presented in Supplemental Fig. 13. No treatment effects were found in the area between the insulin and glucose curves in the GTT performed at 5,10 , or 14 days postpartum $(P=0.5,0.2$, and 0.5 , respectively).

Neutrophil function. For the oxidative burst assay, the MFI and the percentage of PMN with oxidative burst activity were not different between MET and CON at any time point $(P>0.9$; Supplemental Figs. 14 and 15 , respectively). Although the MFI for phagocytosis did not differ between experimental groups $(P=0.7$; Supplemental Fig. 16), the percentage of PMN that engulfed beads at 21 days postpartum tended to be greater for MEL $(P=0.09$; Supplemental Fig. 17). For the DQ-ovalbumin assay the MFI was $27 \%$ greater in MEL at 14 days postpartum $(P=0.008$; Fig. 5$)$.

Endometrial cytology. The PMN percentage in the endometrial cytology samples changed over time $(P<0.05)$, reaching a peak at 14 days postpartum, decreasing until 35 days postpartum for both treatment groups, but did not differ between treatments $(P=0.6$; Fig. 6$)$.

No adverse events (apparent clinical abnormalities or disease events) occurred during the study. 


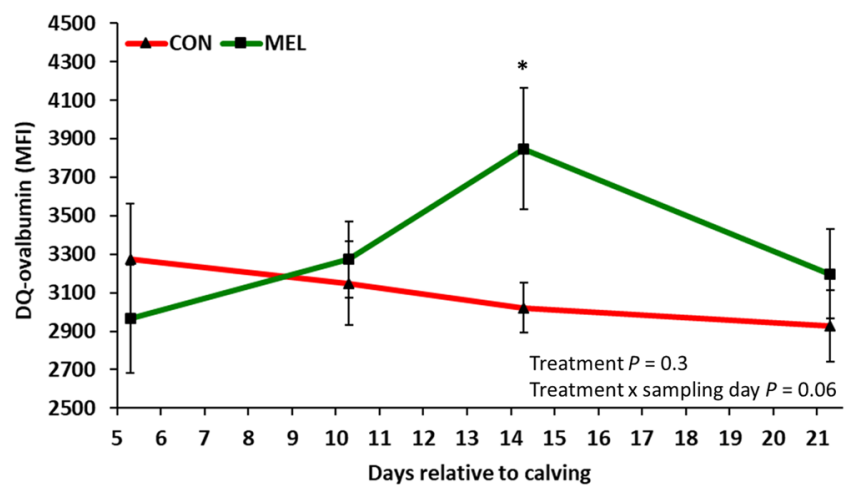

Figure 5. LSM (accounting for parity and body condition score) $\pm S E$ of median fluorescence intensity (MFI) of circulating polymorphonucleated neutrophils (PMN) incubated with DQ-ovalbumin in 42 Holstein cows. Experimental groups consisted of control $(\mathrm{CON} ; \mathrm{n}=22)$ and meloxicam treated cows $(\mathrm{MEL}, \mathrm{n}=20)$. MEL received meloxicam $(0.5 \mathrm{mg} / \mathrm{kg}$ of body weight) once daily for 4 days (10 to 13 days postpartum). MEL had greater DQ-ovalbumin MFI than CON at 14 days postpartum $(P=0.008)$.

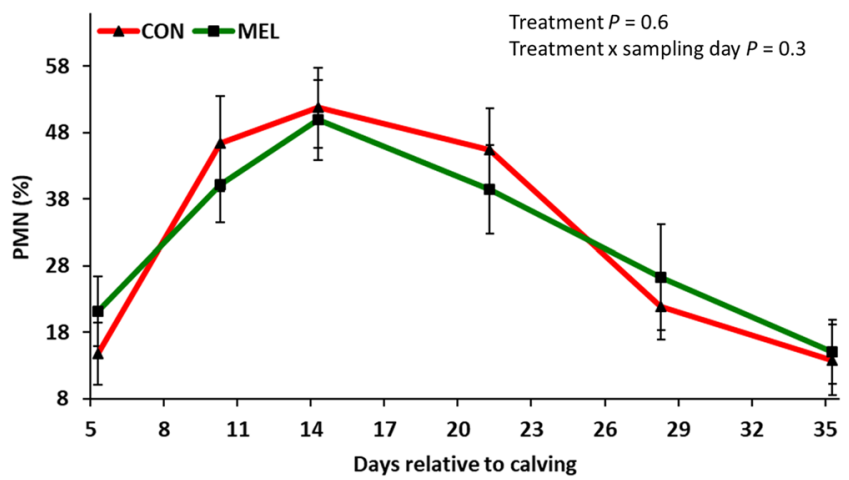

Figure 6. LSM (accounting for parity and body condition score) \pm SE of endometrial polymorphonuclear cells percentage (PMN, \%) of 42 Holstein cows. Experimental groups consisted of control (CON; $n=22)$ and meloxicam treated cows $(M E L, n=20)$. MEL received meloxicam $(0.5 \mathrm{mg} / \mathrm{kg}$ of body weight) once daily for 4 days (10 to 13 days postpartum). The PMN \% was similar between CON and MEL.

\section{Discussion}

This study evaluated the hypothesis that administration of NSAID in the second week after calving could mitigate SI and attenuate endometrial inflammation. Meloxicam treatment decreased serum haptoglobin concentrations (a marker of SI), and improved indicators of adaptative energy metabolism (lesser serum concentrations of BHB, greater glucose and stable IGF-1 in the treatment period). This was associated with modest improvement of one measure of PMN function but did not translate to reduced inflammation of the endometrium.

The foundation of the therapeutic effects of NSAID is through inhibition of COX enzymes, which reduces the formation of prostaglandins ${ }^{40}$. COX exists in two isoforms, the constitutive COX-1 and the inducible COX-2 $2^{41}$. Inhibition of COX-1 accounts for most of the negative side-effects associated with NSAID use, while COX-2 inhibition accounts for the therapeutic effects of NSAIDs ${ }^{42}$. However, a growing body of evidence suggests that NSAID have supplementary anti-inflammatory properties. Treatment with NSAID could modulate transcription factors such as nuclear factor-kappa $\mathrm{B}^{43}$, that controls the inducible expression of many genes involved in inflammation, including TNF- $\alpha$ and IL- $1 \beta^{44}$. Such an effect may explain the decreased concentration of serum haptoglobin from the second until the last day of meloxicam treatment. While expected, to our knowledge, this is the first time this effect has been demonstrated in dairy cattle. This may provide new opportunities to mitigate the well-documented detrimental associations of elevated postpartum haptoglobin concentrations with reproductive health in dairy cows ${ }^{45-47}$.

Glucose is the main fuel used by most cells, but in lactating dairy cows a large portion of hepatic glucose output is directed to the mammary gland to support milk production. Alternative substrates are therefore required for energy metabolism in the peripheral tissue of lactating cows. This partitioning of nutrients in the early postpartum period coincides with a decrease in $\mathrm{DMI}^{48}$, and an increase of metabolic markers associated with NEB, such as NEFA and $\mathrm{BHB}^{49}$. Circulating NEFA concentrations reflect fat mobilization and BHB concentrations reflect the degree of oxidation of fatty acids in the liver ${ }^{50-52}$. Although we found no differences in milk production or DMI between experimental groups during or after meloxicam treatment, BHB concentrations were substantially lower in MEL during treatment. Lower biosynthesis of haptoglobin may improve hepatic metabolism of 
fatty acids. Glucose and IGF-1 concentrations are important markers of adaptation to $\mathrm{NEB}^{53}$. Therefore, our results validate a positive effect of meloxicam treatment on liver function and energy status of postpartum dairy cows, as indicated by decreased serum BHB concentrations and increased serum glucose. Interestingly, serum IGF-1 concentrations were stable during treatment with MEL, but decreased at that time in CON, such that IGF-1 was greater in MEL than CON. The greater concentrations of haptoglobin and BHB during this time in CON might indicate impaired liver health, which could transiently impair IGF-1 synthesis. However, the specific mechanisms behind these results remain to be determined.

Maladaptation to NEB in dairy cows is associated with a decline in PMN function ${ }^{54-56}$. PMN mainly depend on glucose for functions such as chemotaxis and bacterial killing ${ }^{53,57,58}$. High concentrations of NEFA, BHB, and haptoglobin are associated with decreased PMN function ${ }^{25,27,59}$. We observed a modest effect of NSAID treatment on MFI in the DQ-ovalbumin assay 14 days postpartum (the day after the last meloxicam injection). The DQ-ovalbumin assay reflects degradation of ovalbumin after endocytosis and proteolytic digestion ${ }^{60}$. This modest improvement in PMN function may be a result of mitigation of SI and an improved glucose availability for PMN.

Though it is unclear exactly how metabolism and immunity are integrated with endometrial health ${ }^{61}$, there is increased evidence of important roles of SI and liver dysfunction in endometrial inflammation ${ }^{29,62,63}$. A longitudinal study examining the dynamics of endometrial cytology demonstrated that rapid postpartum recruitment of PMN to the uterine lumen was associated with improved fertility ${ }^{20}$. The proportion of PMN in the uterine lumen should reach a peak one to two weeks postpartum and it is important for endometrial health that PMN numbers return to basal levels by the fourth week postpartum ${ }^{19,20}$. Persistently elevated PMN percentage in the endometrium is associated with a substantial reduction in the probability of pregnancy following insemination ${ }^{64}$. While in the current study MEL succeeded in decreasing one measure of SI, improving indicators of energy metabolism, and slightly improving PMN function, this did not translate to a reduction in endometrial inflammation at any time point $\left(14,21,28\right.$ or 35 days postpartum). In two studies in grazing dairy cows ${ }^{29,65}$, administration of a different NSAID at 1,3, and 5 or 19,21, and 23 days postpartum, or 3 injections at intervals of 3 days between 21 and 31 days postpartum, did not have an effect on endometrial health. However, NSAID treatment between 21 and 31 days postpartum increased the pregnancy rate in high-PMN cows. Despite of these improvements in fertility, the authors hypothesized that the lack of effect on the endometrial PMN proportion might be attributable to the timing of treatment and the failure to produce sufficient suppression of inflammation due to the dosing interval. Based on their results, for this study we used a more aggressive treatment regimen for four consecutive days just after the PMN peak as described by Gilbert et al. ${ }^{20}$. This timing of treatment is also coincident with the divergent systemic and uterine inflammatory status in cows later diagnosed with endometritis as reviewed by LeBlanc ${ }^{3}$. The PMN percentage in endometrial cytology reached a peak 14 days postpartum regardless of treatment, and then decreased until 35 days postpartum for both experimental groups. Based on the effect of MEL on serum haptoglobin, treatment appears to have had the intended effect of reducing SI, so the results suggest that of inflammation within the endometrium may be localized, or that the changes in indicators of SI with systemic MEL were insufficient to effect changes in uterine inflammation.

No other measured metabolite or insulin sensitivity (measured via GTT) was influenced by meloxicam treatment in this experiment. Arguably, the repeated sampling for measuring endometrial PMN\% may have created or aggravated inflammation of the endometrium. However, Madoz et al. ${ }^{66}$ did not find an effect of repeated cytobrush sampling ( 4 cytobrush samples in a 4- to 7-day interval) in lactating cows (27 to 56 days postpartum). To the extent that sampling may have created artefacts in endometrial PMN\%, the effect would be equal in both treatment groups. Other studies involving NSAID in the postpartum period appeared to improve liver function, with reductions in plasma AST and $\mathrm{GLDH}^{29}$. Moreover, oral anti-inflammatory medication in the first week postpartum resulted in greater hepatic insulin sensitivity ${ }^{32,67,68}$. Other early postpartum studies with NSAID have been performed, but the metabolic effects are not consistent ${ }^{30}$. The type of NSAID, route and frequency of administration, dosage, and inclusion criteria for animals (only healthy versus including diseased), likely contribute to these discrepancies.

\section{Conclusion}

This study used validated, minimally-invasive biomarkers to evaluate the effects of meloxicam treatment on postpartum inflammation, circulating PMN function, and uterine health in dairy cows. Meloxicam treatment attenuated SI (decreased serum haptoglobin concentrations) and improved indicators of energy metabolism (decreased serum concentrations of BHB and increased glucose and IGF-1). This resulted in slight improvement in PMN function, which did not translate to mitigation of inflammation in the endometrium. Further investigation is warranted to explore the mechanisms of action of anti-inflammatory treatments on SI, energy metabolism, and to optimize the drug dosages, timing, and duration to improve animal health.

Received: 13 January 2020; Accepted: 6 March 2020;

Published online: 23 March 2020

\section{References}

1. McGarry, J. D. What if Minkowski had been ageusic? An alternative angle on diabetes. Science. 258, 766-770 (1992).

2. Linné, Y. Effects of obesity on women's reproduction and complications during pregnancy. Obes. Rev. 5, 137-143 (2004).

3. LeBlanc, S. Monitoring metabolic health of dairy cattle in the transition period. J. Reprod. Dev. 56, 29-35 (2010).

4. Pascottini, O. B. et al. Feed restriction to induce and meloxicam to mitigate potential systemic inflammation in dairy cows before calving. J. Dairy Sci. 102, 9285-9297 (2019).

5. Trevisi, E., Amadori, M., Cogrossi, S., Razzuoli, E. \& Bertoni, G. Metabolic stress and inflammatory response in high-yielding, periparturient dairy cows. Res. Vet. Sci. 93, 695-704 (2012).

6. Bradford, B., Yuan, K., Farney, J., Mamedova, L. \& Carpenter, A. Invited review: Inflammation during the transition to lactation: New adventures with an old flame. J. Dairy Sci. 98, 6631-6650 (2015). 
7. De Koster, J. et al. The contribution of hormone sensitive lipase to adipose tissue lipolysis and its regulation by insulin in periparturient dairy cows. Scientific Reports. 8, 13378 (2018).

8. Huzzey, J. M., Nydam, D. V., Grant, R. J. \& Overton, T. R. Associations of prepartum plasma cortisol, haptoglobin, fecal cortisol metabolites, and non-esterified fatty acids with postpartum health status in Holstein dairy cows. J. Dairy Sci. 94, 5878-5889 (2011).

9. Eckersall, P. D. \& Bell, R. Acute phase proteins: Biomarkers of infection and inflammation in veterinary medicine. Vet. J. 185, 23-27 (2010).

10. McCarthy, M. M., Yasui, T., Felippe, M. J. B. \& Overton, T. R. Associations between the degree of early lactation inflammation and performance, metabolism, and immune function in dairy cows. J. Dairy Sci. 99, 680-700 (2016).

11. Slattery, M. L. et al. Aspirin, NSAIDs, and colorectal cancer: possible involvement in an insulin-related pathway. Cancer Epidemiol. Biomarkers Prev. 13, 538-545 (2004).

12. Fontana, L., Eagon, J. C., Trujillo, M. E., Scherer, P. E. \& Klein, D. Visceral fat adipokine secretion is associated with systemic inflammation in obese humans. Diabetes. 56, 1010-1013 (2007).

13. Drackley, J. K. ADSA Foundation Scholar Award. Biology of dairy cows during the transition period: The final frontier? J. Dairy Sci. 82, 2259-2273 (1999)

14. Seifi, H. A., LeBlanc, S. J., Leslie, K. E. \& Duffield, T. F. Metabolic predictors of post-partum disease and culling risk in dairy cattle. Vet. J. 188, 216-220 (2011).

15. Kasimanickam, R. K. et al. Associations among serum pro- and anti-inflammatory cytokines, metabolic mediators, body condition, and uterine disease in postpartum dairy cows. Reprod. Biol. Endocrinol. 11, 103 (2013).

16. Yasui, T., McCann, K., Gilbert, R. O., Nydam, D. V. \& Overton, T. R. Associations of cytological endometritis with energy metabolism and inflammation during the periparturient period and early lactation in dairy cows. J. Dairy Sci. 97, 2763-2770 (2014).

17. Cheong, S. H. et al. Uterine and systemic inflammation influences ovarian follicular function in postpartum dairy cows. PLoS One. 12, 5 (2017).

18. Sheldon, I. M., Cronin, J. G. \& Bromfield, J. J. Tolerance and innate immunity shape the development of postpartum uterine disease and the impact of endometritis in dairy cattle. Annu Rev Anim Biosci. 7, 361-384 (2018).

19. Prunner, I. et al. Dynamics of bacteriologic and cytologic changes in the uterus of postpartum dairy cows. Theriogenology. 82, $1316-1322(2014)$.

20. Gilbert, R. O. \& Santos, N. R. Dynamics of postpartum endometrial cytology and bacteriology and their relationship to fertility in dairy cows. Theriogenology. 85, 1367-1374 (2016).

21. LeBlanc, S. J. Reproductive tract inflammatory disease in postpartum dairy cows. Animal. 8, 54-63 (2014).

22. Dubuc, J., Duffield, T. F., Leslie, K. E., Walton, J. S. \& LeBlanc, S. J. Definitions and diagnosis of postpartum endometritis in dairy cows. J. Dairy Sci. 93, 5225-5234 (2010).

23. Wagener, K., Gabler, C. \& Drillich, M. A review of the ongoing discussion about definition, diagnosis and pathomechanism of subclinical endometritis in dairy cows. Theriogenology. 94, 21-30 (2017).

24. Gilbert, R. O. Symposium review: Mechanisms of disruption of fertility by infectious diseases of the reproductive tract. J. Dairy Sci. 102, 3754-3765 (2019).

25. Hammon, D. S., Evjen, I. M., Dhiman, T. R., Goff, J. P. \& Walters, J. L. Neutrophil function and energy status in Holstein cows with uterine health disorders. Vet. Immunol. Immunopathol. 113, 21-29 (2006).

26. Ster, C., Loiselle, M. C. \& Lacasse, P. Effect of postcalving serum nonesterified fatty acids concentration on the functionality of bovine immune cells. J. Dairy Sci. 95, 708-717 (2012).

27. Wittrock, J. A. M. Associations among neutrophil function, metabolic indicators, and reproductive Health in Dairy Cows. MSc Thesis, University of Guelph. (2012).

28. Hundal, R. S. et al. Mechanism by which high-dose aspirin improves glucose metabolism in type 2 diabetes. J. Clin. Invest. 109, 1321-1326 (2002).

29. Priest, N. V. et al. The responsiveness of subclinical endometritis to a nonsteroidal anti-inflammatory drug in pasture-grazed dairy cows. J. Dairy Sci. 96, 4323-4332 (2013).

30. Carpenter, A. J. et al. Hot topic: Early postpartum treatment of commercial dairy cows with nonsteroidal anti-inflammatory drugs increases whole-lactation milk yield. J. Dairy Sci. 99, 672-679 (2016).

31. Shock, D. A. et al. Evaluating the impact of meloxicam oral suspension administered at parturition on subsequent production, health, and culling in dairy cows: A randomized clinical field trial. PLoS ONE. 13, e0209236 (2018).

32. Montgomery, S. R. et al. Effects of sodium salicylate on glucose kinetics and insulin signaling in postpartum dairy cows. J. Dairy Sci. 102, 1617-1629 (2019).

33. Matteo, G., Mauro, C. \& Massimo, M. Cows response to glucose tolerance test (GTT) and periparturient diseases: Preliminary study. J. Dairy. Sci. 92, 385. (Abstr.) (2009).

34. Miltenburg, C. L., Duffield, T. F., Bienzle, D., Scholtz, E. \& LeBlanc, S. J. The effect of prepartum feeding and lying space on metabolic health and immune function. J. Dairy Sci. 101, 5294-5306 (2018).

35. Makimura, S. \& Suzuki, N. Quantitative determination of bovine serum haptoglobin and its elevation in some inflammatory diseases. J. Vet. Sci. 44, 15-21 (1982).

36. Skinner, J. G., Brown, R. A. L. \& Roberts, L. Bovine haptoglobin response in clinically defined field conditions. Vet. Rec. 128, $147-149$ (1991).

37. Pascottini, O. B. et al. Technical note: Assessment of neutrophil endocytosis and proteolytic degradation and its relationship with phagocytosis and oxidative burst in dairy cows. J. Dairy Sci. 102, 9396-9400 (2019).

38. Van Schyndel, S. J., Bogado Pascottini, O. \& LeBlanc, S. J. Comparison of cow-side diagnostic techniques for subclinical endometritis in dairy cows. Theriogenology. 120, 117-122 (2018).

39. Pascottini, O. B. et al. Distribution of inflammation and association between active and chronic alterations within the endometrium of dairy cows. Reprod. Domest. Anim. 51, 751-757 (2016).

40. Furst, D. Meloxicam: selective COX-2 inhibition in clinical practice. Semin. Arthritis Rheum. 26, 21-27 (1997)

41. Warner, T. D. et al. Nonsteroidal drug selectivity for cyclo-oxygenase-1 rather than cyclo-oxygenase- 2 are associated with human gastrointestinal toxicity: a full in vitro analysis. Proc. Natl. Acad. Sci. 96, 7563-7568 (1999).

42. Lees, P., Landoni, M. F., Giraudel, J. \& Toutain, P. L. Pharmacodynamics and pharmacokinetics of nonsteroidal anti-inflammatory drugs in species of veterinary interest. J. Vet. Pharmacol. Therap. 27, 479-490 (2004).

43. Díaz-González, F. \& Sánchez-Madrid, F. NSAIDs: learning new tricks from old drugs. Eur. J. Immunol. 45, 679-686 (2015).

44. Barnes, P. J. \& Karin, M. Nuclear factor-kappaB: a pivotal transcription factor in chronic inflammatory diseases. N. Engl. J. Med. 36, 1066-1071 (1997).

45. Huzzey, J. M. et al. Haptoglobin as an early indicator of metritis. J. Dairy Sci. 92, 621-625 (2009).

46. Dubuc, J., Duffield, T. F., Leslie, K. E., Walton, J. S. \& LeBlanc, S. J. Risk factors for postpartum uterine diseases in dairy cows. J. Dairy Sci. 93, 5764-5771 (2010).

47. Galvão, K. N. et al. Association between uterine disease and indicators of neutrophil and systemic energy status in lactating Holstein cows. J. Dairy Sci. 93, 2926-2937 (2010).

48. Grummer, R. R. Impact of changes in organic nutrient metabolism on feeding the transition cow. J. Anim. Sci. 73, 2820-2833 (1995).

49. LeBlanc, S. J. Interactions of metabolism, inflammation, and reproductive tract health in the postpartum period in dairy cattle. Reprod. Domest. Anim. 47, 18-30 (2012). 
50. Vazquez-Añon, M., Bertics, S., Luck, M., Grummer, R. R. \& Pinheiro, J. Peripartum liver triglyceride and plasma metabolites in dairy cows. J. Dairy Sci. 77, 1521-1528 (1994).

51. Adewuyi, A. A., Gruys, E. \& van Eerdenburg, F. Non esterified fatty acids (NEFA) in dairy cattle. A review. Vet. Q. 27, 117-126 (2005).

52. Allen, M. S. \& Piantoni, P. Metabolic control of feed intake: Implications for metabolic disease of fresh cows. Vet. Clin. North Am. Food Anim. Pract. 29, 279-297 (2013).

53. Sheldon, I. M., Cronin, J. G., Pospiech, M. \& Turner, M. L. Symposium review: Mechanisms linking metabolic stress with innate immunity in the endometrium. J. Dairy Sci. 101, 3655-3664 (2018).

54. Kehrli, M. E. Jr., Nonnecke, B. J. \& Roth, J. A. Alterations in bovine neutrophil function during the periparturient period. Am. J. Vet. Res. 50, 207-214 (1989).

55. Gilbert, R. O., Gröhn, Y. T., Miller, P. M. \& Hoffman, D. J. Effect of parity on periparturient neutrophil function in dairy cows. Vet. Immunol. Immunopathol. 36, 75-82 (1993).

56. Cai, T. Q. et al. Association between neutrophil functions and periparturient disorders in cows. Am. J. Vet. Res. 55, 934-943 (1994).

57. Borregaard, N. \& Herlin, T. Energy metabolism of human neutrophils during phagocytosis. J. Clin. Invest. 70, 550-557 (1982).

58. Weisdorf, D. J., Craddock, P. R. \& Jacob, H. S. Granulocytes utilize different energy sources for movement and phagocytosis. Inflammation. 6, 245-256 (1982).

59. Suriyasathaporn, W., Heuer, C., Noordhuizen-Stassen, E. N. \& Schukken, Y. H. Hyperketonemia and the impairment of udder defense: A review. Vet. Res. 31, 397-412 (2000).

60. Underhill, D. M. \& Goodridge, H. S. Information processing during phagocytosis. Nat. Rev. Immunol. 12, 492-502 (2012).

61. Turner, M. L., Cronin, J. G., Noleto, P. G. \& Sheldon, I. M. Glucose availability and AMP-activated protein kinase link energy metabolism and innate immunity in the bovine endometrium. PLoS One 11, e0151416 (2016).

62. Bertoni, G., Trevisi, E., Han, X. \& Bionaz, M. Effects of inflammatory conditions on liver activity in puerperium period and consequences for performance in dairy cows. J. Dairy Sci. 91, 3300-3310 (2008).

63. Burke, C. R. et al. Relationships between endometritis and metabolic state during the transition period in pasture-grazed dairy cows. J. Dairy Sci. 93, 5363-5373 (2010).

64. Pascottini, O. B., Hostens, M., Sys, P., Vercauteren, P. \& Opsomer, G. Cytological endometritis at artificial insemination in dairy cows: prevalence and effect on pregnancy outcome. J. Dairy Sci. 100, 588-597 (2017).

65. Meier, S. et al. Treatment with a nonsteroidal anti-inflammatory drug after calving did not improve milk production, health, or reproduction parameters in pasture-grazed dairy cows. J. Dairy Sci. 97, 2932-2943 (2014).

66. Madoz, L. V. et al. The relationship between endometrial cytology during estrous cycle and cutoff points for the diagnosis of subclinical endometritis in grazing dairy cows. J. Dairy. Sci. 96, 2333-4339 (2013).

67. Farney, J. K. et al. Sodium salicylate treatment in early lactation increases whole-lactation milk and milk fat yield in mature dairy cows. J. Dairy Sci. 96, 7709-7718 (2013).

68. Farney, J. K. et al. Anti-inflammatory salicylate treatment alters the metabolic adaptations to lactation in dairy cattle. Am. J. Physiol. Regul. Integr. Comp. Physiol. 305, 110-117 (2013).

\section{Acknowledgements}

Financial support for this study was provided by the Ontario Ministry of Agriculture, Food and Rural Affairs (Guelph, ON, Canada) and by Boehringer-Ingelheim Vetmedica (Burlington, ON, Canada). Special thanks to Laura Wright (University of Guelph, Guelph, ON, Canada) and the staff at the University of Guelph Livestock Research and Innovation Centre Dairy Facility (Elora, ON, Canada).

\section{Author contributions}

S.J.L. and O.B.P. conception and design of research; O.B.P., S.J.V., J.F.W.S. and M.R.C. performed experiments; O.B.P. analyzed data; O.B.P. and S.J.L. interpreted results; O.B.P. prepared figures; O.B.P., S.J.V. and B.M. drafted manuscript; S.J.L. and E.S.R. edited and revised manuscript drafts and all authors approved final version of the manuscript.

\section{Competing interests}

The authors declare no competing interests.

\section{Additional information}

Supplementary information is available for this paper at https://doi.org/10.1038/s41598-020-62103-x.

Correspondence and requests for materials should be addressed to O.B.P.

Reprints and permissions information is available at www.nature.com/reprints.

Publisher's note Springer Nature remains neutral with regard to jurisdictional claims in published maps and institutional affiliations.

(c) (i) Open Access This article is licensed under a Creative Commons Attribution 4.0 International License, which permits use, sharing, adaptation, distribution and reproduction in any medium or format, as long as you give appropriate credit to the original author(s) and the source, provide a link to the Creative Commons license, and indicate if changes were made. The images or other third party material in this article are included in the article's Creative Commons license, unless indicated otherwise in a credit line to the material. If material is not included in the article's Creative Commons license and your intended use is not permitted by statutory regulation or exceeds the permitted use, you will need to obtain permission directly from the copyright holder. To view a copy of this license, visit http://creativecommons.org/licenses/by/4.0/.

(C) The Author(s) 2020 